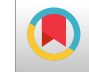

\title{
Prevalence of Elder Abuse and Neglect in Iran: A Systematic Review and Meta-Analysis
}

\author{
Ashraf Ghiasi ${ }^{1, *}$ \\ ${ }^{1}$ Student Research Committee, School of Nursing and Midwifery, Shahroud University of Medical Sciences, Shahroud, Iran \\ "Corresponding author: PhD Student of Reproductive Health, Student Research Committee, School of Nursing and Midwifery, Shahroud University of Medical Sciences, \\ Shahroud, Iran. Tel: +98-2332395054, Email: a.ghiasi25@gmail.com
}

Received 2018 June 19; Revised 2018 August 09; Accepted 2018 August 13.

\begin{abstract}
Context: Elder abuse remains one of the most hidden forms of intra-family conflict within many societies. The purpose of the present systematic review and meta-analysis was to assess the prevalence of elder abuse in Iran.

Methods: International and national electronic databases including Web of Science, PubMed, Scopus, SID, Magiran, Irandoc and Google Scholar were searched from inception to April 22, 2018. The quality of studies was assessed using the "STROBE" checklist. Meta-analysis was performed on studies that used the same questionnaire and reported estimates of annual prevalence of elder abuse.

Results: Of 1386 articles retrieved in the initial search, 13 studies were selected for systematic review, of which eight studies were eligible to be included in the meta-analysis. The overall rates across all forms of abuse ranged widely from $14.7 \%$ to $87.8 \%$. The pooled prevalence rate for overall elder abuse was 60\% (95\% CI: $42 \%$ - 78\%). The pooled prevalence estimate in the domains of elder abuse was 13\% (95\% CI: 7\% - 18\%) for physical abuse, 36\% (95\% CI:24\% - 47\%) for psychological abuse, $31 \%$ (95\% CI: $18 \%$ - $43 \%$ ) for financial abuse, $28 \%$ (95\% CI: $19 \%$ - 37\%) for financial neglect, $36 \%$ (95\% CI: $22 \%$ - 50\%) for care neglect, $43 \%$ (95\% CI: 31\% - 55\%) for emotional neglect, $25 \%$ (95\% CI: $16 \%-35 \%$ ) for authority deprivation, and 13\% (95\% CI: 8\% - 18\%) for abandonment.

Conclusions: The results of the study showed the high prevalence of elder abuse in Iran, which requires the initiation of effective interventions by the legal authorities.
\end{abstract}

Keywords: Elder Abuse, Iran, Meta-Analysis, Prevalence, Systematic Review

\section{Context}

Elder abuse, also called elder mistreatment or elder maltreatment, is "a single or repeated act or lack of appropriate action, occurring within any relationship where there is an expectation of trust that causes harm or distress to an older person" $(1,2)$. This type of violence includes: (i) Physical, sexual, psychological and emotional abuse; (ii) financial and material abuse; (iii) abandonment; (iv) neglect; and (v) serious loss of dignity and respect (3). The health consequences of elder abuse can be especially serious (4). It can destroy a victim's quality of life by declining his functional abilities, increasing dependency, inducing dementia and enhancing the risk of malnutrition or over medication $(5,6)$. Elder abuse can even result in death.

Prospective studies have demonstrated that victims of elder abuse are at a higher risk for premature death than those not reporting abuse, especially in black populations $(7,8)$. Although elder mistreatment is not a new phenomenon, its formal recognition has only occurred over the last 20 to 30 years. A systematic literature review re- ported the prevalence of elder abuse in Asian countries ranged from 0.22 per 1000 to $62 \%$ (9). Yon et al. in a meta-analysis of various countries across the globe found a prevalence rate of $15.7 \%$ for elder abuse (10). Concern over the abuse of older adults has been heightened with the realization that the elderly population will increase dramatically in the coming decades (11). It is predicted that the proportion of the world's population aged 60 years and older will nearly double from about $12 \%$ in 2015 to $22 \%$ in 2050 $(12,13)$. Iran is no exception in this regard.

In 2016, about 9.3\% of Iran's population was 60 years or over, and it is expected to rise to $30 \%$ by 2050 (14). In recent years, several studies have investigated elder abuse in different cities of Iran, but none has systematically summarized them. Hence, regarding the rapid growth of the aged people in this country and the importance of the elder abuse as a factor influencing older adults' health and quality of life, this systematic review was conducted to assess the prevalence of elder abuse and its neglect in Iran. Understanding the magnitude of elder abuse is a crucial 
first step in the public health approach to prevent this type of violence (10). On the other hand, awareness about the frequency of elder abuse facilitates other related studies.

\section{Objectives}

The present systematic review and meta-analysis was performed to determine the prevalence of elder abuse and neglect in Iran.

\section{Methods}

\subsection{Search Strategy}

The following databases were searched between 10 March and 22 April 2018 to identify eligible articles: Magiran, Scientific Information Database(SID), Irandoc, Scopus, PubMed and Web of Science. Databases were searched with no time restriction. The following terms or a combination of them was used for searching in English electronic databases: "aged", "elderly", "older adults", "senior aging", "abuse”, "geriatric", "elder abuse", "elder neglect”, "elder misbehavior", "elder mistreatment", "violence", "prevalence", "cross-sectional", "Iran" and "Iranian". Boolean operators (AND, OR) were used wherever possible. Persian terms equivalent to the English terms mentioned above were used for searching in Persian electronic databases. Google Scholar was also searched to ensure that no article is missed. In a final search, the reference lists of all the included articles were also manually reviewed to identify any additional articles (snowball method). Unpublished studies were not searched in this review.

\subsection{Study Selection Criteria}

The selection process was conducted in three steps. First, the titles of all the collected articles were reviewed and duplicates were removed. Second, abstracts of all the articles that were somehow relevant to the study subject were collected. Finally, studies that investigated the prevalence of elder abuse and neglect in a sample of Iranian elderly population were included in this study. The following were excluded: (1) hospital-based studies, (2) studies with sample sizes less than 100, (3) studies that were not published as full reports like conference abstracts and (4) articles that were not available in their full text.

\subsection{Data Extraction}

The following information was extracted from studies that met the inclusion criteria: study characteristics (the first author, year of publication, year of study and location), study methodology (sampling method and the instrument used to measure elder abuse), characteristics of participants (age and gender), sample size, prevalence rates and other relevant information.

\subsection{Quality Assessment}

The quality of the included studies was assessed based on a modified version of the strengthening the reporting of observational studies in epidemiology (STROBE) checklist (15). This checklist consists of 22 items; scores on each item range from 0 to 2 . A score of 2 is awarded if the "criterion was fully met", 1 if the "criterion was partially met" and 0 if the "criterion was not met". Scores of 0 - 22, 23 - 33 and $34-44$ are defined as low, moderate and high quality, respectively.

\subsection{Statistical Analysis}

The standard errors were calculated by the following formula:

$S E p=\operatorname{sqrt}[p(1-p) / n]$

$p$ is the proportion of successes in the sample and $n$ is the number of observations in the sample. Data were analyzed using RevMan software, version 5.3 (16). Pooled estimates of the prevalence of elder abuse were calculated using the random-effects model.

\section{Results}

\subsection{Literature Search}

On the initial search, 1386 articles were retrieved. After excluding 374 duplicates and 992 irrelevant articles, 20 studies remained for full-text evaluation. Of these, seven studies were excluded because two of them did not contain prevalence information, two had a sample size of less than 100 subjects, one was an abstract from a conference, one was a hospital-based study and full text of the other articles was not available. Finally, 13 articles were considered for the systematic review (Figure 1).

\subsection{Study Characteristics}

The years the studies were performed and published ranged from 2007 to 2015 and from 2008 to 2017, respectively. The total number of participants was 4357 , with a range of 180 to 500 per study. All the 13 included studies were cross-sectional and quantitative in nature. One study reported data only for females (17), while the remainder included male as well as female participants. Eight studies used the Iranian domestic elder abuse questionnaire (17-24), three (25-27) used a researcher-designed questionnaire and two studies $(28,29)$ used the elder assessment instrument. Nine studies $(17-24,27)$ provided past-year prevalence data for abuse and four $(25,26,28,29)$ provided prevalence data for any abuse that had occurred since the victims became older adults (i.e., aged 60 - 65 years and older; Table 1). 

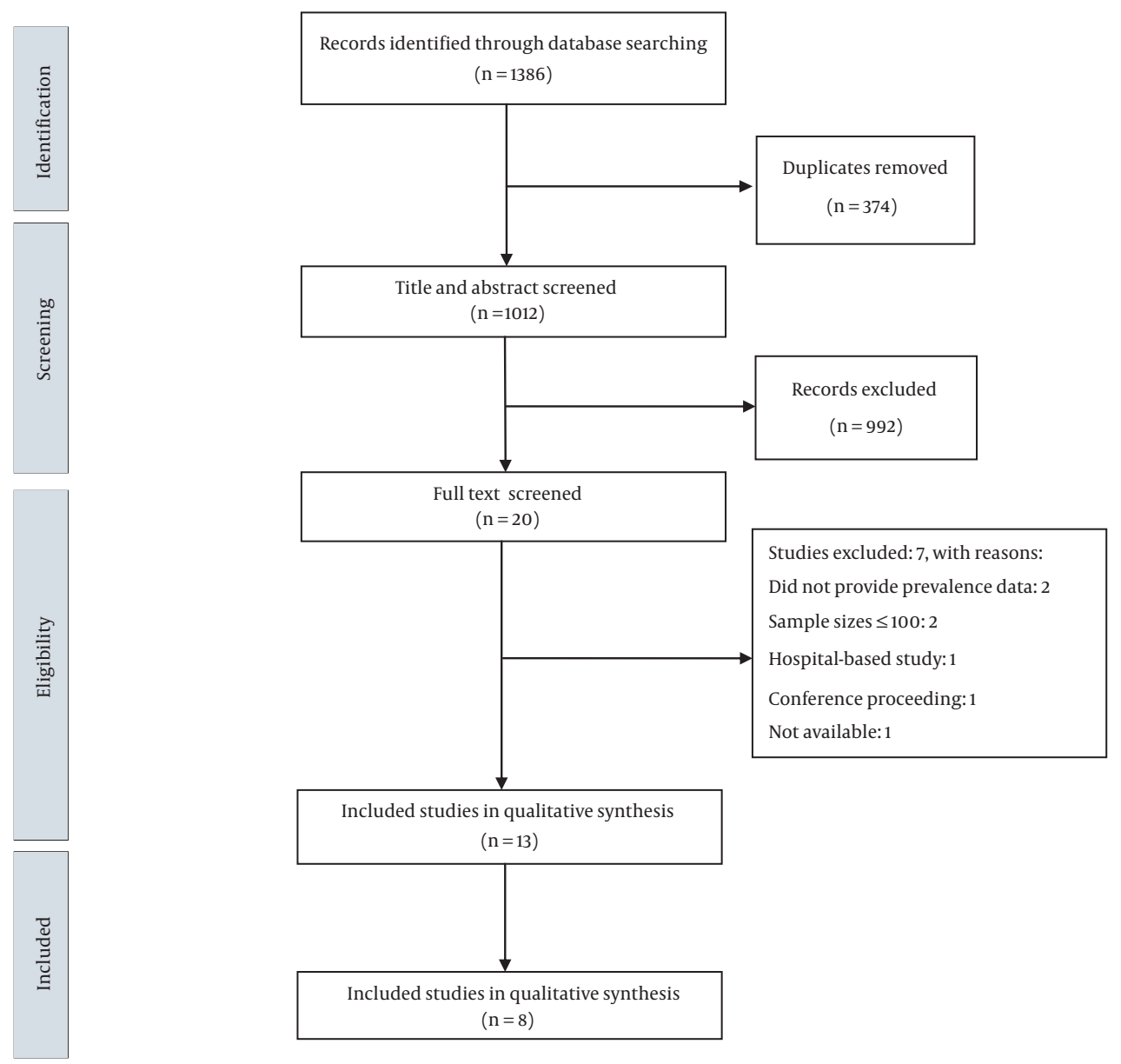

Figure 1. PRISMA flow diagram of literature search and selection process

\subsection{Estimated Prevalence of Elder Abuse}

With regard to differences among instruments in assessing elder abuse, data originally used from 13 studies were on physical, psychological and financial abuse (17-29), 10 studies on abandonment $(17-24,28,29)$, nine studies on care neglect $(17-24,27)$, eight studies on financial neglect, emotional neglect and authority deprivation (17-24), four studies on neglect $(25,26,28,29)$, and 10 studies on overall prevalence of elder abuse and neglect (17, 18, 20-23, 25, $27,28)$. The overall rates across all forms of abuse ranged from $14.7 \%$ in a study from Ahvaz, Iran (27) to $87.8 \%$ in a study from Tehran, Iran (25). With regard to the different forms of abuse, a wide range of prevalence rates was again demonstrated. Rates of physical abuse ranged between $2.8 \%$ (19) and 44.5\% (17), psychological abuse ranged between 3\% (27) and 91\% (26), financial abuse ranged between $3 \%$ (16) and $48.5 \%$ (11), neglect ranged between $14.6 \%$ (29) and $68.3 \%$ (25), emotional neglect ranged between $17.4 \%$ (18) and 69\% (17), care neglect ranged between 7.3\% (21) and 59.8\% (20), financial neglect ranged between 9.8\% (18) and $44.8 \%$ (17), authority deprivation ranged between $10 \%$ (18) and $45.4 \%$ (17) and abandonment rates ranged between $3.7 \%$ (18) and $42.8 \%$ (17).

Eight studies were eligible to be included in the metaanalysis. The criteria for inclusion in the meta-analysis were: (1) Studies that used the same questionnaire and (2) studies that provided past-year prevalence data. Hence, only studies that used Iranian domestic elder abuse questionnaire were eligible for inclusion in the meta-analysis. For the prevalence estimates, we used data from eight studies on physical abuse, psychological abuse, financial abuse, emotional neglect, financial neglect, care neglect, authority deprivation and abandonment (10-24) and six studies on the overall prevalence of elder abuse and neglect $(17,18$, 20-23).

The pooled prevalence rate for overall elder abuse was 60\% (95\% CI: 42\% - 78\%; Figure 2).

The pooled prevalence estimates in the domains of el- 


\begin{tabular}{|c|c|c|c|c|c|c|c|c|c|}
\hline \multirow{2}{*}{$\begin{array}{l}\text { Study or Subgroup } \\
\text { Heravi-2012 }\end{array}$} & \multirow{2}{*}{$\frac{\text { Percent }}{0.259}$} & \multirow{2}{*}{$\frac{\text { SE }}{0.0225}$} & \multirow{2}{*}{$\frac{\text { Weight }}{16.7 \%}$} & \multirow{2}{*}{$\begin{array}{c}\text { Percent } \\
\text { IV, Random, 95\% CI } \\
0.26[0.21,0.30]\end{array}$} & \multicolumn{4}{|c|}{$\begin{array}{c}\text { Percent } \\
\text { IV, Random, 95\% CI }\end{array}$} & \\
\hline & & & & & & & & $=$ & \\
\hline Keyghobadi-2014 & 0.494 & 0.0372 & $16.5 \%$ & $0.49[0.42,0.57]$ & & & & - & \\
\hline Khalili-2016 & 0.8 & 0.0178 & $16.8 \%$ & $0.80[0.77,0.83]$ & & & & & \\
\hline Mohebi-2015 & 0.605 & 0.0337 & $16.5 \%$ & $0.60[0.54,0.67]$ & & & & - & \\
\hline Morowatisharif abad-2016 & 0.796 & 0.0254 & $16.7 \%$ & $0.80[0.75,0.85]$ & & & & & \\
\hline Nassiri-2015 & 0.633 & 0.0223 & $16.7 \%$ & $0.63[0.59,0.68]$ & & & & $=$ & \\
\hline Total $(95 \% \mathrm{Cl})$ & & & $100.0 \%$ & $0.60[0.42,0.78]$ & & & & & \\
\hline \multicolumn{5}{|c|}{$\begin{array}{l}\text { Heterogeneity: } \text { Tau }^{2}=0.05 ; \mathrm{Chi}^{2}=419.47, \text { of }=5(\mathrm{P}<0.00001) ; I^{2}=99 \% \\
\text { Test for overall effect: } Z=6.47(\mathrm{P}<0.00001)\end{array}$} & -1 & $\frac{1}{-0.5}$ & 0 & 0.5 & 1 \\
\hline
\end{tabular}

der abuse were 13\% (95\% CI: 7\% - 18\%) for physical abuse, 36\% (95\% CI: $24 \%$ - 47\%) for psychological abuse, 31\% (95\% CI:18\% - 43\%) for financial abuse, $28 \%$ (95\% CI: $19 \%$ - 37\%) for financial neglect, $36 \%$ (95\% CI: $22 \%$ - 50\%) for care neglect, $43 \%$ (95\% CI: 31\% - 55\%) for emotional neglect, 25\% (95\% CI:16\% $35 \%$ ) for authority deprivation and 13\% (95\% CI: 8\% -18\%) for abandonment (Figure 3).

\subsection{Quality of the Included Studies}

The STROBE scores for the included studies ranged from 25 to 35 out of 44 points (moderate-to-high quality; Table 2).

\section{Discussion}

This systematic review and meta-analysis study, based on a comprehensive search strategy, was conducted to better understand the prevalence of elder abuse and neglect in Iran. Thirteen studies were included in this review, of which eight studies were eligible to be included in the meta-analysis. Quality assessment showed that 4 (30.7\%) studies had high quality and 9 (69.3\%) studies had moderate quality. Of the articles reviewed, nine were published between 2014 and 2017. This growing rate shows that, in recent years, more attention has been paid to the study of elder abuse in Iran. The overall prevalence rates of abuse showed a high variability across studies, ranging from $14.7 \%$ to $87.8 \%$. Although this systematic review identified 13 studies on prevalence, the meta-analysis only focused on studies that used the same questionnaire and reported estimates of past-year prevalence of elder abuse.

Findings from the meta-analysis revealed that the overall prevalence of elder abuse and neglect was $60 \%$. Compared to the reported prevalence rates of elder abuse in other countries, this rate is close to those reported from some countries such as India (49\%), Croatia (61.1\%) and Peru (79.7\%), but the rates reported from Ireland (2.2\%), United
Kingdom (2.6\%), Canada (8.2\%) and United States (10\%) were considerably lower than the result of this review (30-36).

This review also found that prevalence estimates for abuse subtypes were highest for emotional neglect (43\%), followed by psychological abuse (36\%), care neglect (36\%), financial abuse (31\%), financial neglect (28\%), authority deprivation (25\%), abandonment (13\%) and physical abuse (13\%). A study in China showed that the prevalence rates of psychological abuse, caregiver neglect, physical abuse and financial abuse were $27.3 \%, 15.8 \%, 4.9 \%$ and $2.0 \%$, respectively (37). In a national survey on elder abuse and neglect in Ireland, the prevalence rates of $1.3 \%, 1.2 \%, 0.5 \%$ and $0.3 \%$ were reported for financial abuse, psychological abuse, physical abuse and neglect, respectively (33). A study in Egypt reported that neglect was the most common type of abuse (42.4\%), followed by physical abuse (5.7\%), psychological abuse (5.1\%) and financial abuse (3.8\%) (38). The difference in the prevalence of elder abuse in various studies could be the result of different definitions of abuse, different sampling or recruiting methodologies, different instruments for assessing abuse, different levels of vulnerability of the surveyed older people and variability in communities' characteristics and cultural contexts (39).

\subsection{Limitations}

This review has some limitations. Almost in all the included studies, elderly people were relatively healthy; thus, the results should be cautiously extrapolated to all country's older population. The difference in the questionnaires used in the studies was another limitation that prevented us from conducting a meta-analysis for all the available studies.

\subsection{Conclusion}

The present study revealed a high prevalence of elder abuse in Iran. The high prevalence of this problem shows that it is not enough to limit the support of the elderly to 


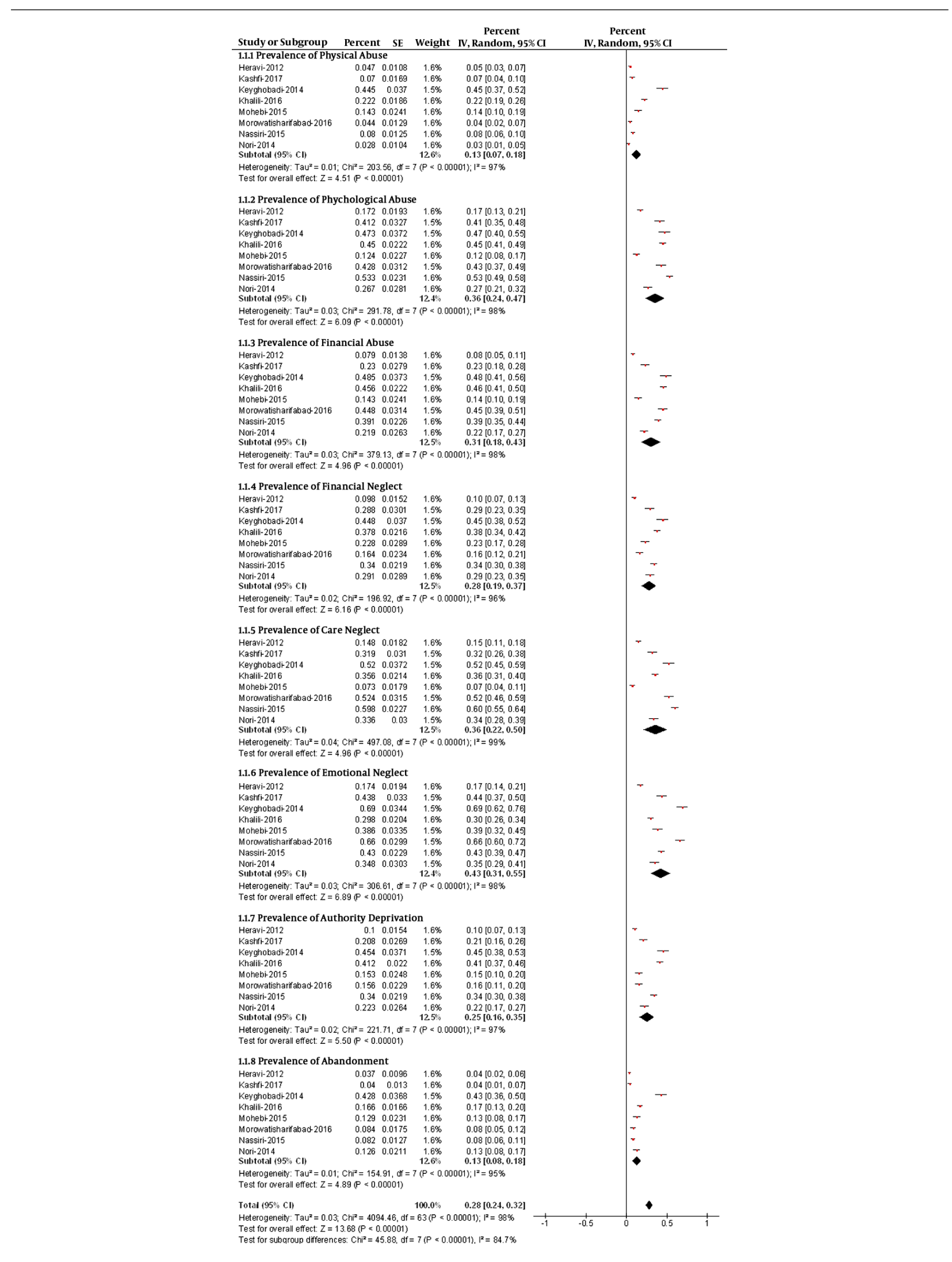

Figure 3. Forest plot of prevalence of elder abuse domains in the elderly in Iran 
culture-building for families and religious teachings. Currently, there is less difference between the laws of ordinary people and the elderly in our country. Therefore, due to the rapid growth of the elderly population in the country, social protection and elderly-related legislation are two main issues for protecting the elderly as one of the most vulnerable strata. Also, due to the limited number of studies in this area in Iran, further research, especially in cities of provinces with large aging populations such as Guilan, is necessary. Studies aiming to assess the prevalence and influencing factors of abuse and negligence against elder people from the perspective of family members, home caregivers and professional nurses are recommended.

\section{Acknowledgments}

The author would like to thank the Student Research Committee at Shahroud University of Medical Sciences.

\section{Footnote}

Funding/Support: This study was financially supported by the Student Research Committee at Shahroud University of Medical Sciences (Grant No. 9780).

\section{References}

1. Vetere PM. Elder abuse: What are we missing? Can Fam Physician. 2011;57(7):783-5. [PubMed: 21753101]. [PubMed Central: PMC3135443].

2. Sooryanarayana R, Choo WY, Hairi NN. A review on the prevalence and measurement of elder abuse in the community. Trauma Violence Abuse. 2013;14(4):316-25. doi: 10.1177/1524838013495963. [PubMed: 23878148].

3. Mikton CR, Tanaka M, Tomlinson M, Streiner DL, Tonmyr L, Lee BX, et al. Global research priorities for interpersonal violence prevention: A modified Delphi study. Bull World Health Organ. 2017;95(1):3648. doi: 10.2471/BLT.16.172965. [PubMed: 28053363]. [PubMed Central: PMC5180342].

4. Pillemer K, Burnes D, Riffin C, Lachs MS. Elder abuse: Global situation, risk factors, and prevention strategies. Gerontologist. 2016;56 Suppl 2:S194-205. doi: 10.1093/geront/gnw004. [PubMed: 26994260]. [PubMed Central: PMC5291158].

5. Comijs HC, Penninx BW, Knipscheer KP, van Tilburg W. Psychological distress in victims of elder mistreatment: The effects of social support and coping.J Gerontol B Psychol Sci Soc Sci.1999;54(4):P240-5. [PubMed: 12382593].

6. Dong X. Medical implications of elder abuse and neglect. Clin Geriatr Med. 2005;21(2):293-313. doi: 10.1016/j.cger.2004.10.006. [PubMed: 15804552].

7. Lachs MS, Williams CS, O'Brien S, Pillemer KA, Charlson ME. The mortality of elder mistreatment. JAMA.1998;280(5):428-32. [PubMed: 9701077].

8. Dong X, Simon MA, Fulmer T, Mendes de Leon CF, Hebert LE, Beck T, et al. A prospective population-based study of differences in elder selfneglect and mortality between black and white older adults.J Gerontol A Biol Sci Med Sci. 2011;66(6):695-704. doi: 10.1093/gerona/glr053. [PubMed: 21498840]. [PubMed Central: PMC3110911].

9. Yan E, Chan KL, Tiwari A. A systematic review of prevalence and risk factors for elder abuse in Asia. Trauma Violence Abuse. 2015;16(2):199219. doi: 10.1177/1524838014555033. [PubMed: 25380662]
10. Yon Y, Mikton CR, Gassoumis ZD, Wilber KH. Elder abuse prevalence in community settings: A systematic review and meta-analysis. Lancet Glob Health. 2017;5(2):e147-56. doi: 10.1016/S2214-109X(17)30006-2. [PubMed: 28104184].

11. Krug EG, Mercy JA, Dahlberg LL, Zwi AB. The world report on violence and health. Lancet. 2002;360(9339):1083-8. doi: 10.1016/S01406736(02)11133-0. [PubMed: 12384003].

12. World Health Organization. World Health Organization; 2015. Available from: http://www.who.int/mediacentre/factsheets/fs404/en/ AccessedMarch25,2016.

13. Bloom DE, Canning D, Fink G. Implications of population ageing for economic growth. Oxf Rev Econ Policy. 2010;26(4):583-612.

14. None. 2018. Available from: https://roozame.com/detail/4693664.

15. Vandenbroucke JP, von Elm E, Altman DG, Gotzsche PC, Mulrow CD Pocock SJ, et al. Strengthening the reporting of observational studies in epidemiology (STROBE): Explanation and elaboration. Epidemiology. 2007;18(6):805-35. doi: 10.1097/EDE.0b013e3181577511. [PubMed: 18049195].

16. Review Manager (RevMan) [Computer program]. Version 5.3. Copenhagen: The Nordic Cochrane Centre, The Cochrane Collaboration 2014.

17. Keyghobadi F, Moghaddam Hosseini V, Keyghobadi F, Rakhshani MH [Prevalence of elder abuse against women and associated factors]. Mazandaran Univ Med Sci. 2014;24(117):125-32. Persian.

18. Heravi Karimoei M, Reje N, Foroughan M, Montazeri A. [Elderly abuse rates within family among members of senior social clubs in Tehran]. Iran J Age. 2012;6(4):37-50. Persian.

19. Nori A, Rajabi A, Esmailzadeh F. [Prevalence of elder misbehavior in northern Iran (2012)]. J Gorgan Univ Med Sci. 2014;16(4). Persian.

20. Nassiri H, Heravi Karimooi M, Jouybari L, Sanagoo A, Chehrehgosha M. [The prevalence of elder abuse in Gorgan and Aq-Qala cities, Iran in 2013]. Iran J Age. 2016;10(4):162-73. Persian.

21. Mohebbi L, Zahednejad S, Javadi Pour S, Saki A. [Domestic elder abuse in rural area of Dezful, Iran and its relation with their quality of life] Iran J Age. 2016;10(4):50-9. Persian.

22. Khalili Z, Taghadosi M, Gilasi H, Sadrollahi A. The prevalence of elder abuse and associated factors among the elderly in Kashan city, Iran.J Bas Res Med Sci. 2016;3(2):26-34.

23. Morowatisharifabad MA, Rezaeipandari H, Dehghani A, Zeinali A Domestic elder abuse in Yazd, Iran: A cross-sectional study. Health Promot Perspect. 2016;6(2):104-10. doi: 10.15171/hpp.2016.18. [PubMed: 27386426]. [PubMed Central: PMC4932221].

24. Kashfi SM, Asadi A, Tabatabaee SH, Yazdankhah M, Khani Jeihooni A Rakhshani T, et al. Elder abuse in Shiraz, Iran. Iran J Psychiatry Behav Sci. 2017;11(2). doi: 10.5812/ijpbs.4667.

25. Manoochehri H, Ghorbi B, Hosseini M, Nasiri Oskuyee N, Karbakhsh $M$. [Degree and types of domestic abuse in the elderly referring to parks of Tehran]. Adv Nurs Midwifery. 2009;18(63):43-50. Persian.

26. Barzanjeh Atri S, Behshid M, Seydi S, Sahebi MH. Abuse to elders living with family in Iran-Tabriz. Int Res J Appl Basic Sci. 2013;4(2):424-9.

27. Alizadeh-Khoei M, Sharifi F, Hossain SZ, Fakhrzadeh H, Salimi Z. Elde abuse: Risk factors of abuse in elderly community-dwelling Iranians. Educ Gerontol. 2014;40(7):543-54. doi:10.1080/03601277.2013.857995.

28. Karimi M, Elahi N. [Elderly abuse in Ahwaz city and its relationship with individual and social characteristics]. Iran J Age. 2008;3(1):42-7. Persian.

29. Hosseini RS, SalehAbadi R, Javanbakhtiyan R, Alijanpouraghamaleki M, Borhaninejad VR, Pakpour V. [A comparison on elderly abuse in Persian and Turkish race in Chaharmahal Bakhtiari Province].J Sabzevar Univ Med Sci. 2016;23(1). Persian.

30. Sebastian D, Sekher TV. Extent and nature of elder abuse in Indian families: A study in Kerala. Help Age India Res Dev J. 2011;17:20-8.

31. Ajdukovic M, Ogresta J, Rusac S. Family violence and health among elderly in Croatia. J Aggress Maltreat Trauma. 2009;18(3):261-79. doi: $10.1080 / 10926770902835873$

32. Silva-Fhon JR, Rio-Suarez D, Defilia A, Motta-Herrera SN, Coelho Fabricio-Wehbe SC, Partezani-Rodrigues RA. Domestic violence in older people living in the district of Breña, Peru. Revista de la Facultad de Medicina. 2015;63(3):367-75. 
33. Naughton C, Drennan J, Lyons I, Lafferty A, Treacy M, Phelan A, et al. Elder abuse and neglect in Ireland: Results from a national prevalence survey. Age Ageing. 2012;41(1):98-103. doi: 10.1093/ageing/afr107. [PubMed: 21997767].

34. Biggs S, Manthorpe J, Tinker A, Doyle M, Erens B. Mistreatment of older people in the United Kingdom: Findings from the first national prevalence study. J Elder Abuse Negl. 2009;21(1):1-14. doi: 10.1080/08946560802571870. [PubMed: 19197619].

35. McDonald L. The mistreatment of older Canadians: Findings from the 2015 national prevalence study. J Elder Abuse Negl. 2018;30(3):176-208. doi: 10.1080/08946566.2018.1452657. [PubMed: 29601283].

36. Acierno R, Hernandez MA, Amstadter AB, Resnick HS, Steve K, Muzzy $\mathrm{W}$, et al. Prevalence and correlates of emotional, physical, sexual, and financial abuse and potential neglect in the United States: The na- tional elder mistreatment study. Am J Public Health. 2010;100(2):2927. doi: 10.2105/AJPH.2009.163089. [PubMed: 20019303]. [PubMed Central: PMC2804623].

37. Wu L, Chen H, Hu Y, Xiang H, Yu X, Zhang T, et al. Prevalence and associated factors of elder mistreatment in a rural community in People's Republic of China: A cross-sectional study. PLoS One. 2012;7(3). e33857. doi:10.1371/journal.pone.0033857. [PubMed: 22448276]. [PubMed Central: PMC3309016].

38. Abdel Rahman TT, El Gaafary MM. Elder mistreatment in a rural area in Egypt. Geriatr Gerontol Int. 2012;12(3):532-7. doi: 10.1111/j.14470594.2011.00780.x. [PubMed: 22212376].

39. Cohen M. Screening tools for the identification of elder abuse. J Clin Outcome Manage. 2011;18(6):261-70. 


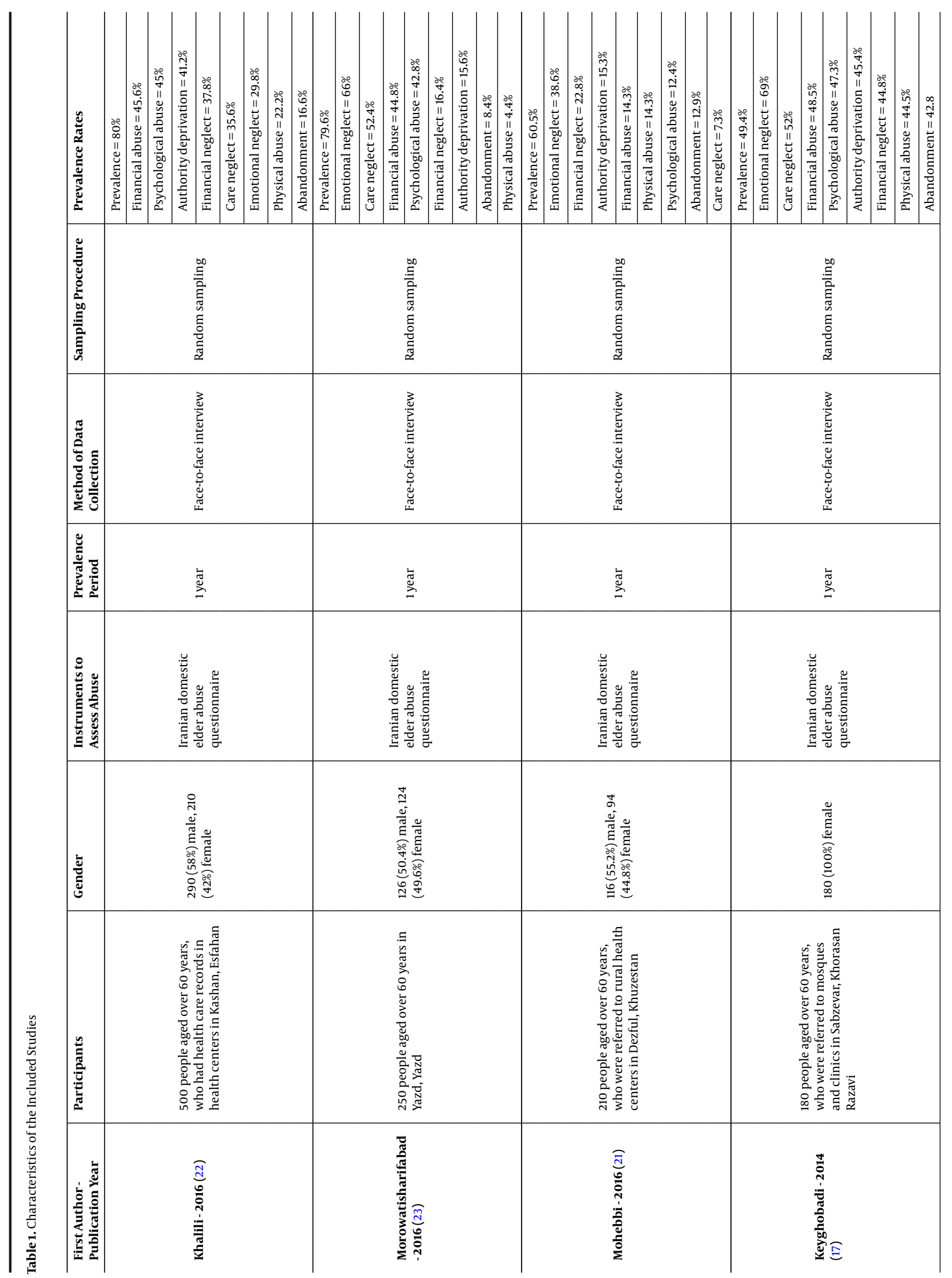




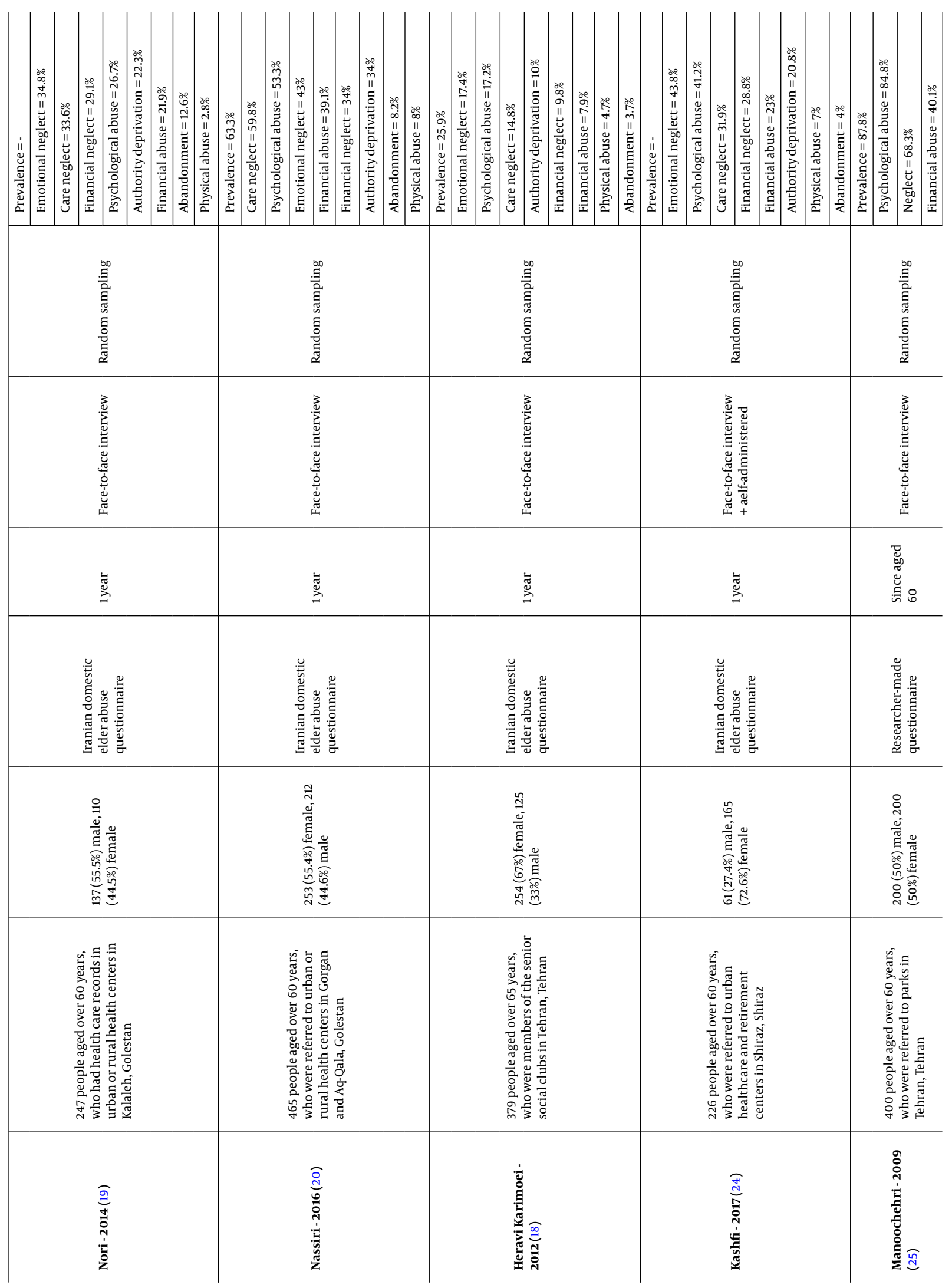




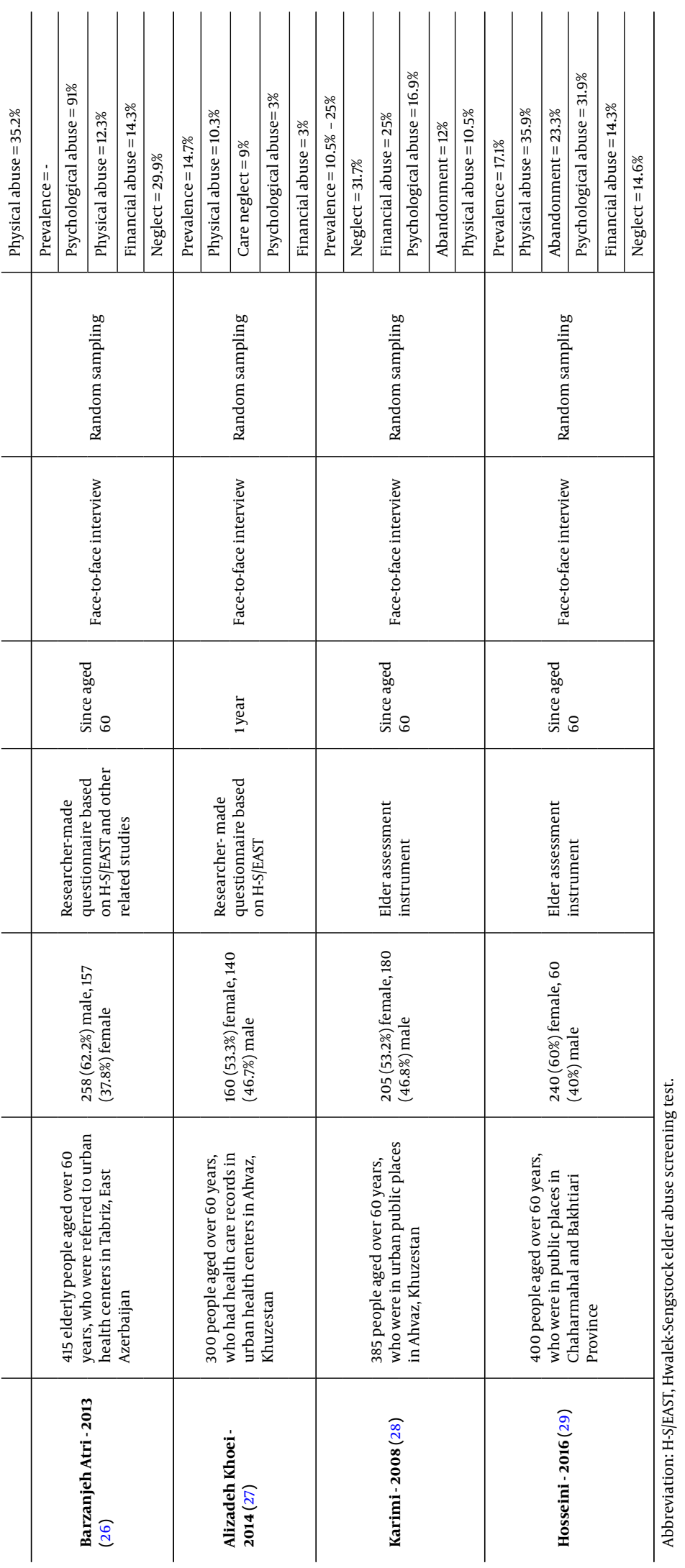


Ghiasi A

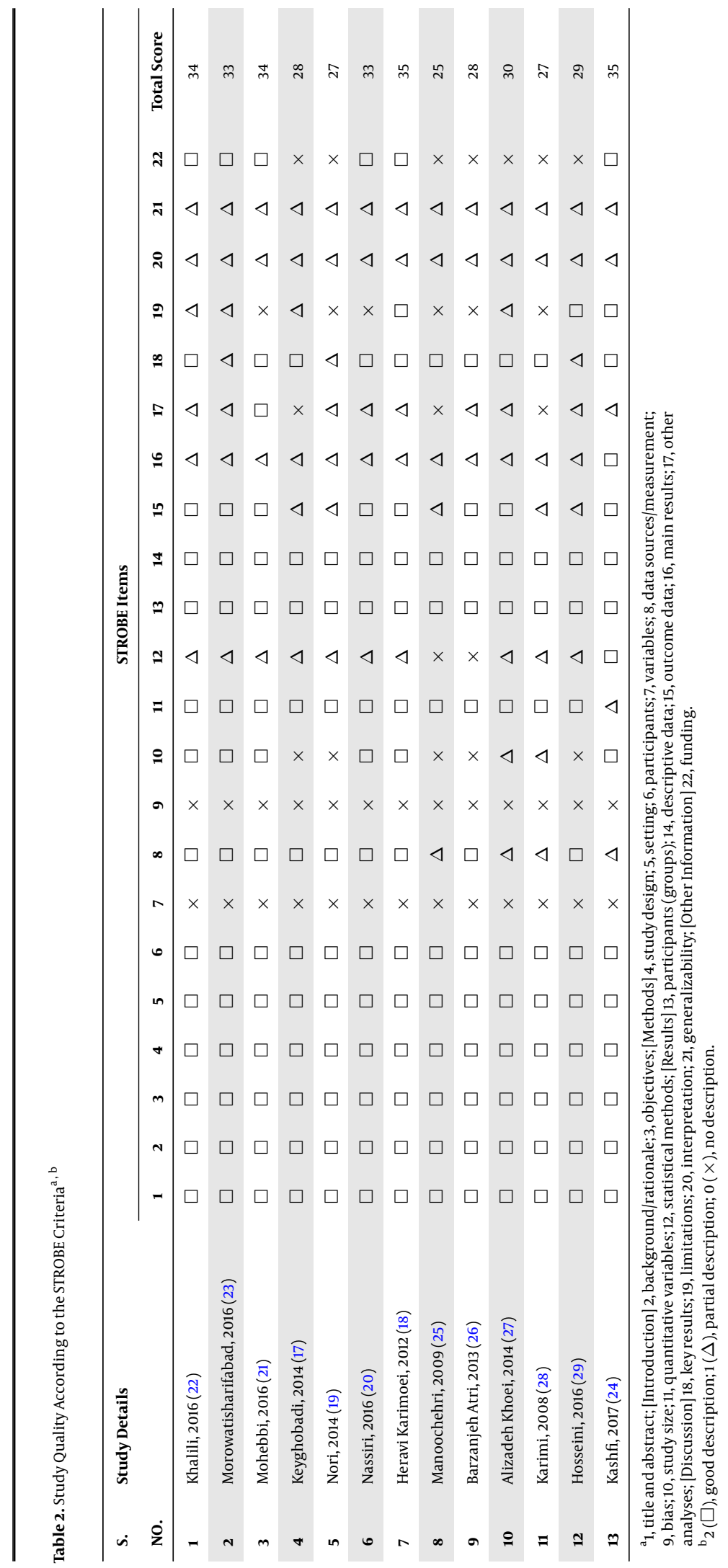

Shiraz E-Med J. 2018; 19(11):e81045.

11 